\title{
MEMORIAS CRUZADAS DE LA GUERRA \\ COLONIAL PORTUGUESA Y LAS LUCHAS DE LIBERACIÓN AFRICANAS: DEL IMPERIO A LOS \\ ESTADOS POSCOLONIALES
}

\author{
CROSSED MEMORIES OF THE PORTUGUESE \\ COLONIAL WAR AND THE AFRICAN LIBERATION \\ FIGHTS: FROM THE EMPIRE TO THE \\ POSCOLONIAL STATES
}

\author{
Miguel CARDINA y Bruno Sena MARTINS* \\ Universidade de Coimbra
}

\begin{abstract}
Resumen: Entre los años 1974 y 1975, el fin de un ciclo de conflictos armados entre el Estado portugués y los movimientos de liberación africanos daría origen a dos importantes transformaciones: en Portugal, la ruptura con la dictadura del Estado Novo; en las antiguas colonias africanas, el surgimiento de un conjunto de naciones nuevas marcadas por el anticolonialismo. Este artículo propone examinar cómo se ha conformado en Portugal la memoria de la guerra colonial confrontándola con una historia colonial más amplia, caracterizada por una memoria selectiva que tiende a suprimir la dimensión violenta del proceso. Esas «políticas de silencio» se oponen a las "políticas de exaltación» de las luchas de liberación nacional que, surgiendo de los antiguos territorios colonizados, fueron institucionalizando versiones de la historia y horizontes de memoria alternativos.
\end{abstract}

Palabras Clave: Colonialismo, anticolonialismo, memoria histórica, políticas de la memoria, Portugal, África.

\footnotetext{
${ }^{*}$ Este artículo ha ido elaborado en el ámbito de los proyectos CROME -Crossed Memories, Politics of Silence. The Colonial-Liberation War in Postcolonial Times-, financiado por el European Research Council en el ámbito del programa marco comunitario de investigación e innovación Horizonte 2020 de la Unión Europea (StG-ERC-715593) y ECHOES Historicising Memories of the Colonial War-, financiado por la Fundaçáo para a Ciência e a Tecnologia (IF/00757/2013). El texto original portugués ha sido traducido al español por María Luisa Aznar Juan. Los autores son investigadores del Centro de Estudios Sociais de la Universidade de Coimbra. miguelcardina@gmail.com; bsenamartins@gmail.com
} 
Aвstract: In 1974/75, the end of a cycle of armed conflict between the Portuguese state and the African liberation movements would lead to two important changes: in Portugal, the break with the Estado Novo dictatorship; in the former African colonies, the emergence of a set of new nations marked by the anticolonialism. This article proposes to examine the memory of colonial war in Portugal confronting it with a wider colonial history, marked by a memorial selectivity that tends to erase the violent dimension of the process. These "politics of silence» are confronted with the "politics of exaltation» of the national liberation struggles that, from the former colonized territories, were instituting alternative regimes of historicity and memory horizons.

KeY words: Colonialism, Anticolonialism, Historical Memory, Politics of Memory, Portugal, Africa.

A partir de 1961 tienen lugar las guerras coloniales entre Portugal y los diferentes movimientos de liberación, cuyo objetivo era conseguir la independencia de los territorios africanos que estaban bajo el dominio colonial. La guerra, como último estertor de un Imperio ya anacrónico, se extendió en tres frentes, primero en Angola y después en Guinea y Mozambique. En Portugal cientos de miles de jóvenes fueron arrancados de la «Metrópolis» para luchar en una guerra lejana. A esta realidad se sumarían los contingentes de reclutamiento locales, que se incorporaron al ejército portugués bajo un proceso de «africanización» de las fuerzas armadas portuguesas que creció a medida que avanzaba la contienda. Los trece años de conflicto resultaron en más de 8.000 soldados muertos y unos 30.000 heridos solo en las tropas portuguesas. No existen datos completos y fiables sobre las víctimas que hubo entre la población civil y los guerrilleros de los movimientos de liberación.

Nacida en la gesta de las luchas anticoloniales de la post Segunda Guerra Mundial este extenso conflicto armado serviría, directa o indirectamente, como antecámara definidora de la independencia de Angola, Cabo Verde, Guinea-Bissau, Mozambique y Santo Tomé y Príncipe. A pesar de las diferencias históricas entre los territorios, las guerras de liberación fueron la marca fundacional, non exenta de ambigüedades, de la creación de las nuevas naciones. Como puso en evidencia el historiador João Paulo Borges Coelho, es necesario integrar también, en el análisis de los conflictos civiles que surgieron tras la independencia, el papel que tuvo el "potencial de violencia» que la militarización de los espacios coloniales había originado durante la guerra (Coelho, 2003). Si todavía es evidente el impacto del pasado colonial en la definición de las fronteras geográficas, en 
la falta de inversión económica y de infraestructuras y en el muy bajo nivel de alfabetización de la población, la guerra, además de producir una propagación considerable de las armas en el país, causó grandes movimientos de desplazamiento de las poblaciones y flujos de migración interna que dejaron a los nuevos países el desafío de acomodar a un número muy significativo de desplazados y refugiados (Chabal, 2002: 30-50). De hecho, el lastre histórico que cargaban las sociedades de las excolonias tiene un peso ineludible en su pasado colonial, aunque haya sido frecuentemente desvalorizado en el análisis y la percepción pública sobre el presente de estos países.

La guerra es el origen en Portugal de la creación del Movimiento de las Fuerzas Armadas (MFA), que el 25 de abril de 1974 provocará el golpe militar que derrumbaría la larga dictadura del Estado Novo y que abriría el camino a un período revolucionario que marcará genéticamente la democracia portuguesa (Rosas, 2016: 79). Hasta el momento actual el significado de la guerra se ha establecido a través de diferentes instancias de memorialización y olvido, que la definen como insurgencia fundadora, doloroso epílogo del imperio o episodio último de una vasta historia de violencia colonial.

\section{Violencia colonial, memoria y eurocentrismo}

En este sentido, apelar a las historias que se cruzan y las memorias que sobrevivieron a las diferentes latitudes de la guerra es, igualmente, una manera de no apagar los tiempos de la violencia colonial en cuanto un elemento constitutivo de la secular empresa ultramarina de ultramar de Portugal, como nos recuerdan las impresionantes cifras del tráfico atlántico de esclavizados (Bethencourt, 2013: $188)^{1}$. Este designio nos confronta con las políticas del silencio con las que los estados europeos, instalados en una memoria eurocéntrica, se relacionan, aun conservando la difícil etiqueta de la violencia colonial como parte de las narrativas fundadoras del capitalismo global y la modernidad occidental. Se trata, de algún modo, de confrontar las «líneas abismales de la modernidad» (Santos, 2014) con la evidencia de que Portugal, lejos de estar aislado en su vínculo con una desmemoria aprendida, comparte con muchos otros antiguos imperios coloniales europeos una descolonización por cumplir, aquella que resultaría del

1 Véase también http://www.slavevoyages.org/ 
pleno reconocimiento de la senda colonial como parte central de la experiencia de la modernidad occidental.

En las sociedades cuyas representaciones del pasado reposan en una matriz eurocéntrica encontramos, reiteradamente, como rasgo característico una profunda omisión de la violencia colonial que forjó el sistema-mundo moderno, iniciado con la expansión colonial europea. Nos referimos a una violencia que, además de genocidios, conversiones forzadas, eliminación de identidades personales y colectivas, desaparecimiento de lenguas y culturas ancestrales, guerras y procesos de esclavitud, siempre se articuló con una violencia racial que tutela las relaciones más básicas de la vida cotidiana, creando mundos en los que, como decía Frantz Fanon, el sujeto colonial tenía que aprender, antes que nada, a quedarse en su lugar, a no sobrepasar sus límites (2004: 15).

El desafío de superar una memoria pública establecida sobre los términos dominantes de la modernidad eurocéntrica es triple. En primer lugar, implica que consideremos como elementos constitutivos de la realidad material, simbólica y política, que hegemónicamente se denomina "Occidente», toda una suerte de historias e instituciones que han tenido lugar fuera de los límites que definen ahora la geografía europea. Aquí el reto no es solo el de reconocer realidades sociales e históricas que han sido silenciadas, sino el de convocar, traduciendo visiones del mundo que permanecen ininteligibles dentro de los ceñidos modos de representar una alteridad que ha sido relegada, según las demandas cognitivas y materiales de una idea de Europa y su proyecto colonial (Said, 1997; Mudimbe, 1998; Dussel, 1995).

En segundo lugar, implica el rechazo a la arrogancia celebratoria que ve en Europa la cuna de una civilización con vocación liberadora y universalista, denunciando la insostenibilidad de un linaje que consagra, como preciosos y singulares legados europeos, el renacimiento iluminista, la democracia y los derechos humanos (Fanon, 2004; Nkrumah, 1973; Mutua, 2001; Rajagopal, 2009). Se trata de reconocer y superar el prejuicio colonial, que impide que el mundo eurocéntrico aprenda de las experiencias y los conocimientos de las personas que han sufrido y sufren, en las diferentes regiones del mundo, las iniquidades de un panorama global fuertemente organizado según los principios de las ambiciones universalistas de la modernidad occidental (Santos, 2018). Tales conocimientos son esenciales para confrontar los procesos de elisión promovidos por la empresa colonial, exponer las resistencias que le sobrevivieron y, finalmente, para mostrar cómo el Sur Global sigue siendo el espacio donde se sufren, en primer lugar, 
los efectos de las fuerzas históricas mundiales, orquestadas por el capitalismo moderno; siendo, además, el lugar donde a menudo se prefiguran las luchas y tensiones que marcan el futuro del Norte Global (Comaroff y Comaroff, 2012).

En tercer lugar, el rescate de una memoria no eurocéntrica implica considerar de una manera sofisticada la contradicción, sumamente cartografiada por Partha Chatterjee $(1986 ; 1993)$, que se refiere a cómo las luchas anticoloniales encontraron en el Estado-Nación moderno, de matriz occidental, el modelo en el que asentaron las comunidades imaginadas que emergían del colonialismo. Si, por un lado, la concepción de nuevas comunidades se rindió a la forma moderna occidental, asumida por los estados poscoloniales que resultaron de la independencia, por otro, esto se llevó a cabo a través de una afirmación de culturas e historicidades que se idearon exactamente contra las jerarquías impuestas por la dominación colonial. Esto implica reconocer que, desde una dimensión formal e institucional, el nacionalismo anticolonial mimetizó la movilización de recursos hegemónicos que sedimentan la idea de Estado: bandera, himno, héroes, historia nacional. Aun así, de manera a veces paradójica, consagró al «dominio espiritual» un lenguaje capaz de contraponerse y visibilizar políticamente la violencia del colonialismo y de forjar una comunidad capaz de sobrevivirle en un escenario poscolonial.

Los pasados de guerra y la violencia, dependiendo de las comunidades de memorialización, quedan sintetizados en espacios sociales de celebración y denuncia o se apagan, como si no existieran. La compleja relación entre los testimonios de la guerra, que existen a partir de diferentes biografías, cuerpos y lugares de enunciación, su implicación en la transformación de subjetividades y la fuerza de las comunidades políticas para determinar de forma recursiva la revisita de lo que fue creado y aniquilado nos muestra cómo los Estado-Nación europeos, en su relación con el colonialismo, constituyen, desde nuestro punto de vista, mundos proverbialmente situados.

\section{La guerra colonial y las políticas del silencio en Portugal}

A la vez que podemos identificar la denegación de la violencia colonial en Portugal como parte de una narración eurocéntrica, contagiada por un modelo de poder colonial que Aníbal Quijano (2005) denominó colonialidad, es de máxima relevancia comprender de qué modo esa narrativa nos remite a las 
características específicas del imperio portugués y las circunstancias que condujeron a su decadencia. El hecho de que el fin del colonialismo portugués haya sido consecuencia de un largo conflicto armado que movilizó importantes recursos y contingentes militares, hace que la guerra colonial se configure como un estudio de caso singular sobre cómo una nación post-imperial y democrática logró formarse dándole la espalda a la guerra que la engendró. Las razones del silenciamiento de la violencia colonial y, a su vez, de la guerra como una de sus expresiones últimas y particulares, tienen una historicidad propia que se articula con la forma en que Portugal imaginó su relación colonial. Ya definida como un «impensado» (Lourenço, 2014), esa relación fue siendo encubierta por narrativas ideológicas que consistieron en la naturalización de lo colonial a través de dispositivos jurídicos, políticos, sociales y discursivos que lo caracterizan y lo representan como no-colonial.

El conflicto denominado "guerra colonial» y también "guerra de ultramar» -esta última expresión usada por el Estado Novo que todavía persiste en determinados sectores sociales y militares- nunca tuvo una presencia en el espacio público en Portugal que correspondiese a su impacto social y político. Sin embargo, tal desaparición pública permanecería tras la implantación de la democracia, a pesar de los cientos de miles de soldados, a los que se sumarían las poblaciones residentes en los territorios coloniales, que regresaron con vívidos recuerdos de la guerra o del derrumbe del Imperio. Cabe, por tanto, entender las razones que pudieron cimentar una desmemoria constitutiva, ya sea en lo que se refiere a una historia de siglos de colonialismo, ya sea en lo que se refiere a la guerra colonial.

En primer lugar, cabe destacar la relevancia que asumieron los denominados "Descubrimientos», o sea, las exploraciones marítimas de los siglos XV y XVI en la definición de una identidad colectiva épica, teñida de valor y universalismo y regularmente convocado. Esta idea de una nación que «dio nuevos mundos al mundo» surge evocada, aún hoy, en los más diferentes ámbitos: en la política, el deporte, el turismo o la publicidad. Asimismo, considerada frecuentemente por el sentido común como un momento preliminar, casi sinónimo del proceso de colonización, corresponderá en el marco del llamado «Tercer Imperio» (o sea, el ahondamiento de la presencia colonial en África) como antecámara legitimadora del papel civilizador y cristianizador de Portugal. Esta idea de una época áurea de los Descubrimientos comenzó a adquirir relevancia a finales del siglo XIX, destacándose en ese proceso el momento de la conmemoración del Tricentenario de Camóes, autor de la epopeya en verso Os Lusíadas, obra del siglo XVI. 
Curiosamente, el acontecimiento fue dinamizado por sectores republicanos que se basaron en las grandes fiestas civiles de la República Francesa y que se apropiarían de este nuevo imaginario nacional exaltante de una época heroica, políticamente movilizado en el contexto del Ultimato inglés (1890) y en las luchas por la instauración de la República (1910). Posteriormente cabrá a la dictadura del Estado Novo, establecida en la década de 1930, profundizar esa «mística imperial» cuyos ejemplos públicos notables serán la Exposición Colonial de Oporto (1934), con más de un millón de visitantes, y la Exposición del Mundo Portugués (1940), con cerca de tres millones de visitantes. La verdad es que, de hecho, ese imaginario ha llegado de manera reconfigurada hasta el presente con una plasticidad relativa y con un éxito evidente: basta pensar en eventos como la Expo 98, centrada en el mar y la importancia de Portugal en la «época de los Descubrimientos» o, más recientemente, el debate en torno a la idea lanzada por la candidata ganadora del Ayuntamiento de Lisboa de construir en la ciudad un «Museu da Descoberta».

En segundo lugar, la visión del colonialismo sufriría un cambio con la adopción casi oficial por parte del Estado Novo del lusotropicalismo como modelo interpretativo de la experiencia colonial portuguesa, llegado a definirla como algo diferente y más benigno en comparación con las experiencias coloniales de otras potencias europeas. La teoría desarrollada por Gilberto Freyre en la década de 1930 en el contexto de Brasil, tendría una fuerte recepción entre las élites políticas en Portugal desde mediados de la década de 1950 (Castelo, 1999), cuando sustituyó a las tesis de carácter más claramente racista, usadas para apoyar la legitimidad del «Imperio Colonial Portugués», designación que el Acto Colonial de 1930 había instituido. Destacando la capacidad innata de los portugueses de mezclarse y de adaptase culturalmente, el lusotropicalismo no solo se incorporó en las élites del régimen, sino que también tuvo una expresión visible en la cultura de masas durante las últimas décadas de la dictadura (Cardão, 2015).

Criticada por intelectuales comprometidos como Mário Pinto de Andrade, fundador del MPLA (Movimiento Popular para la Liberación de Angola), que, en 1956, bajo el pseudónimo de Buanga Felê, hacía la anatomía de esa "teoría sociológica de encargo" ["teoria sociológica de encomenda»] (Felê, 1956), las tesis lusotropicalistas se utilizaron internacionalmente para resistir a las presiones resultado de la oleada descolonizadora que comenzó durante la posguerra. Aunque la expresión hoy en día no tenga repercusión pública, la idea de una excepcionalidad histórica de Portugal se mantiene viva y alimenta un cierto «nacionalismo banal» (Billig, 1995), marcado por mecanismos discursivos que, 
en el propio lenguaje oficial y en momentos conmemorativos del Estado (Loff, 2014; Cardina, 2016), omiten los procesos más relacionados con la violencia y la guerra y destacan una singular vocación universalista. Esta genérica y persistente representación del colonialismo influyó naturalmente en la forma en que (no) se recuerda la guerra, en la medida en que se constituye como un violento desmentido de la saludable convivencia entre pueblos hermanos que el proceso histórico había entrecruzado.

En tercer lugar, cabe reconocer el papel relativamente limitado de las oposiciones al Estado Novo en la negación del colonialismo. Es importante señalar, en este sentido, qué representaciones lusotropicalistas fueron fortalecidas por el régimen colonial-fascista sin que la oposición propiamente dicha lograra producir y anclar socialmente las lecturas, representaciones y propuestas alternativas. Es cierto que los anarquistas y un movimiento negro embrionario en la década de los años 20 lo intentaron (Garcia \& Castro, 1995; Varela \& Pereira, 2019) y que la concepción del Partido Comunista Portugués (PCP), sometida a numerosas configuraciones (Manya, 2004; Neves, 2008; Madeira, 2013), afirmaría claramente el derecho de los pueblos africanos a la independencia. Sin embargo, varias figuras del ámbito republicano eran defensores declarados de la presencia colonial portuguesa y los mismos socialistas mantuvieron una posición ambigua durante la década de los años sesenta, condenando la política colonial y afirmando ya tarde el derecho a la independencia de los pueblos colonizados (Martins, 2005: 178-9). El PCP, principal fuerza organizada de la oposición, mantuvo una política de unidad antifascista con los sectores republicanos que objetivamente contribuiría a marginar el abordaje de la cuestión colonial.

Limitada a formas más o menos ritualizadas de participación durante los actos electorales falsos o remitida a la clandestinidad, ya tardíamente la oposición llevó a cabo una lucha anticolonial que, aun así, fue un combate más contra la guerra colonial que un combate contra el colonialismo, sus prácticas y sus consecuencias. Raramente se trató, pues, de un combate que tuviera una amplitud social que permitiese articular una agenda anticolonial y antirracista. Un nuevo impulso fue dado por otras áreas de la política en el campo de la izquierda radical (maoístas, marxistas-leninistas, trotskistas, socialistas radicales, católicos progresistas, etc.), lo que en 1960, en Portugal y también en el exilio, supondría una contribución para una creciente conciencia crítica sobre la guerra, denunciando los crímenes del colonialismo y defendiendo la negativa de la participación en la guerra, pero su impacto se concentró principalmente en los sectores juveniles urbanos y escolarizados (Bebiano, 2005; Cordeiro, 2009; Cardina, 2011). 
En cuarto lugar, mientras avanzaba, la guerra colonial estaba sujeta a mecanismos institucionales e informativos específicos. Cuando el conflicto estalla, Portugal no reconoce estar enfrentando una guerra, sino acciones armadas dentro de un mismo territorio nacional llevadas a cabo por «terroristas». A esto debe sumarse una cultura de resignación que estaba determinada, entre otros aspectos de naturaleza histórica y social, por la criminalización y demonización del debate político. Era la eficacia de lo que el historiador Fernando Rosas designa como "violencia preventiva», ese conjunto de órganos de vigilancia, de orden público y de inculcación ideológica, que incitaban a la obediencia y que limitaban fuertemente la expresión de posicionamientos contrarios a la norma social y la política definida por el Estado Novo (Rosas, 2012: 196-202). Además, hay que añadir la voluntad activa del régimen de ocultar de la sociedad el impacto de la guerra, desconsiderando el apoyo institucional a los combatientes y a las familias de militares muertos y heridos. Las familias de los militares muertos recibían la noticia en una carta con una cinta negra y con una información lacónica y formal del Estado; los heridos desembarcaban de noche y los mantenían encerrados en hospitales destinados para ellos (Gomes, 2004: 173). Embarcaban así en un régimen de invisibilidad, que se perpetuaría en el post- 25 de abril, particularmente registrado en el cuerpo de aquellos que regresaron heridos y que se constituyeron como la expresión viva de un duro recuerdo que el orden social democrático quiso olvidar (Martins, 2013). En este sentido, es común encontrar testimonios de ex combatientes como Francisco Pereira, un asociado de ADFA que después de participar durante años en los diversos frentes de la Guerra Colonial, quedaría marcado por el peso de los recuerdos traumáticos:

¡La guerra siempre continuó y continúa! ¡Aquí adentro! Si escucho, no diré una puerta, pero un golpe más fuerte, jinmediatamente me pongo en alerta! ¡Todavía recuerdo ese shock! Si es: «Bum!» —un golpe seco... Vivo allá cerca del Cuartel, en una aldea, y cuando lanzan esas granadas más fuertes, si las escucho de primera, si no me doy cuenta que son fuegos artificiales todavía me pongo en alerta, muy en alerta. Eso fue poco después de dejar de caminar con una pistola en la mano. (...) Por la noche, cuando me iba a dormir, todo lo demás, la guerra, siempre volvía. Vuelve y sé que nunca dejará de volver. Por mucho que lo quiera olvidar, no lo olvido (Entrevista personal, 2015). 
En quinto lugar, es importante comprender las implicaciones que tuvo que la Revolución de los claveles de 25 de abril de 1974 se produjese en estrecha relación con la guerra colonial. El Movimiento das Fuerzas Armadas, que condujo el golpe que derribaría el Estado Novo, y abriría las puertas a un intenso proceso revolucionario, estaba compuesto esencialmente por militares de rango intermedio que optaron por imponer una solución a una guerra que estaba políticamente perdida. Esta íntima relación entre el proceso que estableció el régimen democrático y la guerra colonial, a través de la figura de los militares, interfirió necesariamente en el debate público sobre la guerra, especialmente en sus vertientes más sangrientas. De hecho, la guerra acabaría siendo vista más como la antecámara de la llegada de la democracia y un acontecimiento dramático a contracorriente con la historia y menos como un episodio dentro del largo tiempo de la presencia en África y la violencia colonial que supuso. A este respecto, la contradicción es solo aparente. El hecho de que el orden político democrático y poscolonial estuviese cimentada en una fortísima aportación de militares, necesariamente inmersos en muchos de los indecibles de la guerra, no permitió la existencia de una límpida voluntad con respecto a lo que sería su evocación condenatoria.

En sexto lugar es transcendental señalar que en el contexto de la independencia africana un número significativo de alrededor de 500 mil portugueses vinieron de África, principalmente, de las antiguas colonias de Angola y Mozambique (Pires, 1987). Gran parte de la literatura académica sobre esta experiencia de «retorno" se ha centrado en su «integración» en la sociedad portuguesa, existiendo pocos estudios sobre los imaginarios políticos que trajeron y su peso en la sociedad portuguesa del post- 25 de abril, aunque sea legítimo suponer que la «memoria infeliz» que cargaban -la memoria de una interrupción abrupta de vidas casi siempre sin contacto directo con los escenarios de guerra, la memoria de la turbulencia de una «descolonización» que los alcanzó directamente- haya interferido en la representación de un colonialismo configurado ora como dulzura de los trópicos, ora como traumático alejamiento.

En séptimo lugar destacamos la articulación entre memoria y territorio. Efectivamente, para entender el conflicto memorial sobre la guerra -y en última instancia sobre la dimensión violenta del colonialismo- debe tenerse en cuenta este último aspecto. A pesar de los grandes contingentes de tropas enviadas para combatir en los tres escenarios africanos -que regresaron de allí con la guerra inscrita en el cuerpo y en la mente, y que tantas veces la transmitieron de forma dramática en su entorno doméstico- lo cierto es que la guerra tuvo lugar lejos de 
territorio portugués. No fue en Portugal donde circularon las tropas, donde los caminos se llenaron de minas, donde se sucedieron los ataques y los bombardeos, donde se desplazaron poblaciones de su lugar de origen, donde se producían las micro y macro violencias propias de las guerras. Estos hechos tienen un impacto indiscutible en el modo de recordar, creando una "memoria sin suelo", en este caso agravada por el hecho de que la guerra se desarrollase en lugares lejanos territorialmente y también cultural y ambientalmente muy diferentes ${ }^{2}$.

Este conjunto de razones dio forma a la manera en que se ha recordado la guerra en Portugal, que constituyó una específica configuración productora de políticas del silencio, a pesar de algunos cambios observables en las últimas cuatro décadas. En la década de 1980, en un contexto de compleja construcción de un Portugal democrático, europeo y poscolonial, la guerra ocupaba un lugar de difícil manifestación. En un ambiente en el que las invocaciones heroicas de la guerra tendrían poco apoyo, la memoria de la guerra circuló entre un silenciamiento cada vez mayor y un conjunto de memorializaciones subalternas: en los espacios privados y las memorias generacionales e intergeneracionales.

Sería en la década de 1990 cuando la memoria de la guerra ganaría mayor visibilidad en el país, con la inauguración en 1994 de un gran «Monumento aos Combatentes do Ultramar», resultado de la colaboración entre las estructuras públicas y la Liga de los Combatientes, recuperando así la designación con la que el Estado Novo, caracterizaba el conflicto: «guerra do ultramar», en lugar de una guerra "colonial», cuya incorrección resultaba de que Portugal no reconociese tener colonias, sino - desde la revisión constitucional de 1951- «provincias ultramarinas» y de la aplicación en 1999 del concepto de «discapacitado de las Fuerzas Armadas»: "perturbación psicológica crónica resultante de la exposición a factores traumáticos de estrés durante la vida militar». Al analizar el monumento en su contexto y en las apropiaciones de las cuales está revestido, Elsa Peralta lo considera un «espacio de luto, no sólo para los familiares de aquellos que murieron en las guerras coloniales, sino también para el conjunto nacional (...) al tiempo que, hace pasar los abusos del colonialismo portugués a través del filtro de una pedagogía de la "exaltación del amor a Portugal"» (Peralta, 2013: 403).

2 Esa distancia, además, ha dado lugar, muy recientemente, a fenómenos como los relacionados con el denominado "turismo de la nostalgia», en el que excombatientes regresan a territorios donde combatieron para reencontrarse con su pasado (particularmente a Guinea). 
A partir de la década de 1990 aumentaron por todo el país el número de encuentros y convivencias de excombatientes, los libros de memorias, los blogs y los monumentos que evocan a los fallecidos y la valentía y esfuerzo por la Patria. Se creó así un espacio en el que se instauró la idea del combatiente como una víctima de una guerra a la que fue arrastrado y de la que sufriría secuelas. En las últimas dos décadas la guerra ha servido de telón de fondo a reflexiones de naturaleza artística, historiográfica y testimonial y se ha alojado en la memoria pública a partir de algunos recortes de experiencias vividas. De manera general y dominante, estas prácticas tienden todavía a destacar el hecho de que se trató de un conflicto armado (una «guerra»), dejando en un segundo plano el hecho de que se produjese dentro de un cierto orden que llegó a ser denominado colonialismo.

\section{Memorias cruzadas}

Los procesos que definen la memoria de la guerra colonial en Portugal lo han hecho, como hemos visto, a la luz de politicas del silencio sólidamente asentadas, ya sea en una representación imperial, ya sea en los dispositivos de una narrativa eminentemente nacional en la que convergen diferentes imperativos, historias sociales y legados. Por tratarse de un acontecimiento relativamente reciente, que envuelve a grupos importantes de población y una multitud de factores geopolíticos, la revisita de la guerra se puede hacer desde varios puntos de vista que van más allá de las contingencias de un determinado nacionalismo metodológico y epistemológico. De hecho, existen muchas perspectivas llamativas que permiten una evocación de la guerra en cuanto expresión del colonialismo, violencia colonial, racismo o derecho a la autodeterminación de los pueblos africanos. En el ámbito portugués, por las razones ya aludidas, estas perspectivas, aunque sea de un modo subalterno, las podemos reconocer en las reivindicaciones de grupos cuya historia de opresión y silenciamiento se confunde con la omisión de la guerra o del colonialismo - caso de negros/as y afrodescendientes (Martins, 2018) o discapacitados de las Fuerzas Armadas (Martins, 2016) - o de colectivos desencadenadores de narrativas contra-memoriales, como es el caso, entre otros, de los exiliados y desertores (Cardina, 2017).

Siendo cierto que las perspectivas que en Portugal disputan una determinada desmemoria del colonialismo nos invitan a la pluralización de representaciones del pasado con un potencial contra hegemónico, creemos que la descentralización crítica de una narrativa benévola sobre las naciones europeas post-imperiales 
nunca será hecha sin un movimiento que reconozca el protagonismo de los mundos creados a partir de los territorios colonizados antiguamente. Se trata, pues, de observar espacios de significado que a menudo todavía son vistos en Occidente como «zonas de no ser» (Fanon, 1952), zonas consideradas expropiadas, aunque sean especialmente susceptibles de generar un resurgimiento. El resurgimiento que aquí se propone es el que resultará del cruce de las representaciones de la guerra colonial y que considere los procesos memorativos que se formaron a partir de las luchas anticoloniales como la antesala de la independencia de Angola, Cabo Verde, Guinea Bissau, Mozambique y Santo Tomé y Príncipe.

De hecho una cosa es recordar la guerra en la antigua metrópoli, donde hoy figura como espectro de un imperio tutelado por un largo régimen dictatorial, y otra es recordarla en las antiguas colonias que, a través de ella, obtuvieron la independencia política. En este último caso, la lucha armada proporcionó a los movimientos de liberación un principio de legitimidad política que rápidamente los convirtió en el motor de la construcción de los nuevos Estados africanos. Dependiendo de los países y períodos históricos, se crearon, de forma discriminada, mecanismos y modos de representación del pasado, fundamentalmente apoyados en la celebración de los movimientos de liberación nacional, la visibilidad pública de las «masacres fundadoras» y la definición de los héroes individuales y figuras prototipo de la liberación.

Así pues, es relevante observar igualmente dos significantes (guerra colonial y lucha de liberación) exponiendo diferentes lugares de enunciación: guerra colonial o guerra de ultramar, expresiones utilizadas en Portugal, y luchas de liberación, término utilizado en los países africanos. Cuando nos referimos a la guerra colonial/guerra de ultramar y la lucha de liberación como términos que en Portugal y en los Estados poscoloniales sitúan los violentos enfrentamientos armados en la decadencia imperial portuguesa, el hecho más destacado es la forma en la que la desmemoria en la antigua metrópoli contrasta con la celebración de la lucha en los estados africanos que sobrevivieron. Dado que la guerra construyó la realidad poscolonial que une la historia reciente de Portugal a la de sus antiguas colonias, hecho que nos aproxima a una comprensión poscolonial sobre la permanencia del colonialismo, reconocida o negada de modo fantasmático, el cruce de memorias que aquí proponemos pretende contrariar una descripción de Portugal que minimice o apague tanto a las víctimas del colonialismo como a las resistencias que lo confrontaron. Nos acercamos a lo que afirma Edward Said cuando, refiriéndose a una mirada retrospectiva del archivo cultural, señala la necesidad de volver a leer «no unívoca, sino contrapuntualmente, con una 
consciencia de la historia metropolitana que se narra y de las otras historias contra y con las que opera el discurso dominante» (Said, 1993: 51).

Reconocer cómo se representan y memorializan las luchas de liberación en los países africanos que alcanzaron la independencia supone, como afirmaba anteriormente Edward Said, contribuir para una conciencia simultánea de la historia metropolitana y de las historias que se le opusieron. De hecho, el impacto de las luchas de liberación define de tal modo los sucesivos presentes de Angola, Cabo Verde, Guinea-Bissau, Mozambique y Santo Tomé y Príncipe, mucho tiempo después de la independencia, la realidad social y política de estos Estados poscoloniales no se puede entender mínimamente sin las marcas que dejaron la insurgencia armada o, de manera más general, la resistencia y la lucha anticolonial. No es sorprendente, pues, que las relaciones de poder establecidas en estos países dependan de la construcción de narrativas históricas y de las legitimidades políticas y simbólicas que se unen a la lucha de liberación. Además, este dato se refleja de modo claro en el papel que los movimientos de liberación asumieron en los diferentes países.

Exceptuando el caso de Guinea, cuya independencia fue proclamada unilateralmente por el PAIGC (Partido Africano para la Independencia de Guinea y Cabo Verde) en septiembre de 1973, las otras antiguas colonias portuguesas en África formalizan su independencia en 1975. La historia de la lucha de cada una fueron diferentes. En Angola hubo tres movimientos que se batieron con armas contra el colonialismo: MPLA (Movimiento Popular de Liberación de Angola), UPA/FNLA (Unión de los Pueblos de Angola y Frente Nacional de Liberación de Angola) y UNITA (Unión Nacional para la Independencia Total de Angola). La UPA/FNLA quedaría ligada a la gran revuelta ocurrida en marzo de 1961 en la que murieron miles de blancos y trabajadores negros en las haciendas del norte de Angola, lo que acabó desencadenando una feroz reacción por parte de los colonos. Surgida en 1966, la UNITA también llevó a cabo varios ataques contra los portugueses, hasta que hizo un pacto de no agresión con el ejército portugués a cambio de información sobre el MPLA y la UPA/FNLA. Surgido de la lucha de liberación y de los conflictos que se siguieron, será el MPLA quien, aun impulsando una larga guerra con la UNITA que acabó en el 2002, se hará cargo del gobierno del país hasta el momento actual. Parafraseando a Christine Messiant, eso es lo que generó en el caso angoleño lo que se podría designar como «imprevisibilidad del pasado», en la cual se singulariza el papel del MPLA -de su «precocidad» en la lucha, de los acontecimientos que desencadenó, de sus dirigentes y héroes- en el movimiento anticolonial y en la construcción de 
una Angola independiente (Messiant, 1998), que las tendencias historiográficas recientes han ido diversificando gradualmente ${ }^{3}$.

En el caso de Mozambique fue esencialmente el FRELIMO (Frente de Liberación de Mozambique) que, a partir de 1964, desencadenaría acciones armadas contra el colonialismo portugués. Tras la independencia tendría un papel decisivo en el gobierno del Estado, enfrentando una guerra prolongada con la RENAMO (Resistencia Nacional de Mozambique) hasta 1992. El historiador João Paulo Borges Coelho habla de la existencia de un «script de la liberación» en el que no solo se hace coincidir la lucha anticolonial moderna con la historia del FRELI$\mathrm{MO}$, como se construye un «discurso estratégico situado en la intersección de las relaciones de poder y las relaciones de saber» que se constituye como la base de su autoridad política (Coelho, 2013).

En el otro frente de guerra, en Guinea, el PAIGC condujo una batalla que en realidad perseguía la doble liberación de Guinea y Cabo Verde. Dirigida por la carismática figura de Amílcar Cabral fue, por acaso, la lucha más exitosa, no solo por haber conseguido controlar parte sustancial del territorio, sino también por la gran simpatía internacional que suscitó. Después de 1980, con el golpe de Estado en el que Nino Vieira depuso a Luis Cabral, acabaría la relación umbilical entre Guinea y Cabo Verde, determinada por la idea de tener dos Estados y el mismo partido dirigente. En Guinea, Cabo Verde y Santo Tomé y Príncipe -donde no hubo lucha armada pero se conquistó la independencia con el MLSTP utilizando la misma gramática anticolonial que sus congéneres africanos- la introducción de mecanismos de democracia liberal y la apertura al mercado, concretizada en la década de 1990, conduciría a que en determinados momentos se pusieran en duda a las élites oriundas de la lucha, junto con disputas sobre la fijación de la narrativa historiográfica (sobre el caso de Cabo Verde, véase: Furtado, 2016).

Como se puede comprobar el ejercicio de escrutinio de las memorias de la lucha de liberación en los diferentes países de africanos, nos remite a un tiempo que, lejos de haber prescrito, define los términos de lo que Partha Chatarjee denominaba el «dominio espiritual» anticolonial del Estado-Nación poscolonial (1986; 1993). Esto sucede por causa de la legitimidad reclamada por parte de los partidos herederos de los movimientos que hicieron la lucha anticolonial, por el lugar que la lucha ocupa en cuanto factor determinante que prefiguró la

3 Véanse, a este respecto, los textos de Maria de Conceição Neto, Marcelo Bittencourt, Fidel Reis, Aida Freudenthal, Paulo Lara y Vasco Martins en Cardina y Martins (2018). 
existencia de los Estados (las celebraciones del día de la independencia dan este testimonio) y, también, por la multiplicidad de factores políticos cuyos poderes se afirman en estrecha relación, a veces de oposición, con la aludida narrativa del «script de liberación».

La constitución de Estados-Nación, cuya independencia se afirmó contra la dominación colonial, originó un contexto marcado por la tensión entre la herencia colonial -con sus fronteras, jerarquías y modos de administración- y la posibilidad de nuevos comienzos. Cuando la independencia es el resultado de la resistencia anticolonial, el diseño de nuevos comienzos se efectúa en estrecha relación con la legitimidad de aquellos que hicieron la guerra. Se entiende así que, por regla general y sobre todo en un primer momento histórico, el «guerrillero» asumió importancia como figura prototipo de la liberación en detrimento de la figura del preso político, el militante clandestino y las retaguardias logísticas aseguradas por las poblaciones, por no hablar de la resistencia protagonizada por incontables hombres y mujeres a lo largo de los tiempos en las diversas áreas de la vida colonial.

La manera como las herencias coloniales se confunden con las exaltantes expectativas producidas por las distintas independencias define, en gran medida, el panorama de la rememoración de los símbolos y fechas de la lucha de liberación. Por un lado, tenemos la legitimidad fuertemente conferida a los movimientos que emergen de la genealogía que se encuentra entre la lucha por la liberación y la independencia. Estos movimientos -sobre todo el PAIGC, el FRELIMO y el MPLA - fundados por el capital simbólico de una lucha que vio cumplido el objetivo de la liberación colonial, crearon un conjunto de expectativas fuertemente alentadas por las alianzas del internacionalismo tricontinental, el panafricanismo anticolonial y el socialismo. Por otro lado, tenemos el modo como los países emergentes estaban siendo confrontados con las diferentes adversidades marcadas por la transición de una economía colonial, por las denominadas guerras civiles que, en el caso de Angola y Mozambique, continuaban y originaban conflictos alimentados por las luchas de la Guerra Fría y las alianzas blancas en el África Austral (Rodesia y Sudáfrica). En este contexto, el conocimiento historiográfico desarrollado en los últimos tiempos sobre el «Ejercicio Alcora» es educativo. El «Ejercicio Alcora» fue una alianza, nunca reconocida públicamente, que Portugal estableció con Sudáfrica y Rhodesia en 1970 para consolidar la soberanía blanca en el sur de África durante la lucha contra los movimientos nacionalistas africanos. Esta alianza permite comprender las continuidades entre el aparato militar de la guerra colonial y las fuerzas que, después de la independencia de 
los territorios bajo dominio portugués, siguieron luchando en las guerras civiles de Angola y Mozambique (Meneses, Rosa y Martins, 2013; Afonso y Gomes, 2013).

A estos factores hay que ańadir el modo como los países poscoloniales se enfrentaron a la victoria política del neoliberalismo a escala global y a los consecuentes dictámenes de las instituciones internacionales. En realidad, el «ajuste estructural» en África determinó, en gran medida, que en los horizontes de la memoria la democracia surgiera como sinónimo de privatizaciones, de creciente relevancia de las ONGs y de una reducción del papel del Estado (Comaroff y Comaroff, 2012). En un panorama marcado por la presencia de partidos únicos, nacidos de los movimientos de liberación, guerras y/o inestabilidad política, y marcado por la permeabilidad de las realidades nacionales y elites locales a las lógicas del capitalismo internacional, en los países africanos las celebraciones de las luchas de liberación tanto congregaban una narrativa nacional anticolonial como suscitaban lecturas ahora desencantadas, ahora que pretendían destituir del poder a aquellos que políticamente fueron reclamando la legitimidad de la lucha que creó la nación.

De hecho, los términos de la memorización de la guerra están fuertemente definidos, en cada contexto, por el modo en que se articulan con las narrativas de la formación de la nación (o en el caso portugués de su resignificación). Podríamos decir que, en cierto modo, se produce un cierre constitutivo de los términos del debate sobre los diferentes tipos de nación que triunfaron en la posguerra. Es decir, las «ruinas del imperio» (Stoler, 2008) desde muy temprano fueron movilizadas a narrativas y memorias nacionales que apenas se comunicaban entre sí. Se crea así una curiosa paradoja. Por un lado, la guerra fue un fenómeno «compartido», en la medida en que involucró vínculos de diversa orden entre movimientos y naciones, suscitando alianzas transnacionales y embates experimentados contiguamente desde diferentes lados; por otro lado, se apeló a las memorias de guerra para definir cada nación a modo de ramificaciones divergentes. Nos encontramos ante lo que Edward Said denominó «experiencias discrepantes» (1993: 31-42), lecturas e interpretaciones que engendraron historias y contextos sociales imposiblemente comunicantes. Citando a Said, en lo que se refiere a la guerra colonial/luchas de liberación, estamos ante la fuerza de aquello a lo que designamos memorias discrepantes, que nos reportan al modo como la imaginación de comunidades nacionales singulares y el eurocentrismo transformaron historias comunes en guiones que resisten a una yuxtaposición y comparación entre visiones potencialmente creadoras de nuevos saberes y perspectivas. 
Por lo tanto, podemos decir que las fuerzas políticas que dominaron la posguerra en Portugal nos remiten a políticas del silencio determinadas por un desentendimiento memorial en relación con la dimensión violenta de la guerra y el reconocimiento del colonialismo. Ahora, en los estados poscoloniales dominaron politicas de exaltación de la lucha que tanto hacían un justo homenaje al levantamiento armado que puso fin al imperio portugués en África, como procuraban definir la legitimidad marcada por la participación en la resistencia armada. En este contexto, las relaciones a las que nos referimos entre los diferentes panoramas de la memoria sobre la guerra colonial procuran, por un lado, valorar la memoria de las luchas de liberación como una contribución para reconocer el pasado y la violencia colonial a partir de instancias de enunciación plural; por otro lado, procuran asumir que estas memorias en los varios países africanos también han sido movilizadas por los mandos de poder que forjaron los regímenes que después de la independencia cimentaron el Estado poscolonial.

\section{Bibliografía}

Afonso, Aniceto; Gomes, Carlos de Matos (2013). Alcora - O Acordo Secreto do Colonialismo Portugal, África do Sul e Rodésia na última fase da guerra colonial, Lisboa: Objectiva.

Bebiano, Rui (2005). "Contestação ao regime e tentação da luta armada sob o marcelismo", Revista Portuguesa de História, n. ${ }^{\circ}$ 37, pp. 65-104.

Bethencourt, Francisco (2013). Racisms. From the Crusades to the Twentieth Century, Princeton \& Oxford: Princeton University Press.

Billig, Michael (1995). Banal Nationalism, London: Sage Publications.

Cann, John P. (1997). Counterinsurgency in Africa. The Portuguese Way of War, 19611974, Westport, Connecticut: Greenwood Press.

CARdão, Marcos (2015). Fado tropical. O luso-tropicalismo na cultura de massas (19601974), Lisboa: UNIPOP.

Cardina, Miguel (2011). Margem de Certa Maneira. O maoismo em Portugal (19641974), Lisboa: Tinta-da-China.

Cardina, Miguel (2016). «Memórias Amnésicas? Nação, discurso político e representaçóes do passado colonial», Configuraçóes, n. ${ }^{\circ}$ 17, pp. 31-42.

Cardina, Miguel (2017). «Olhar o avesso da guerra», Prefacio a Exilios 2. s/l: Associaçóes de Exilados Políticos Portugueses.

ÉNDOXA: Series Filosóficas, n. 44, 2019, pp. 113 - 134. UNED, Madrid 
Cardina, Miguel y Martins, Bruno Sena (2018). As Voltas do Passado. A guerra colonial $e$ as lutas de libertação, Lisboa: Tinta-da-China.

Castelo, Cláudia (1999). O modo português de estar no mundo. O luso-tropicalismo e a ideologia colonial portuguesa (1933-1961), Porto: Afrontamento.

Chabal, Patrick; Birmingham, David; Forrest, Joshua; Newitt, Malyn; Seibert, Gerhard y Andrade, Elisa Silva (2002). A History of Postcolonial Lusophone Africa, London: Hurst.

Chatterjee, Partha (1986). Nationalist thought and the colonial world: a derivative discourse? London, U.K.

Chatterjee, Partha (1993). The Nation and its Fragments: colonial and postcolonial histories, Princeton: Princeton University Press.

Cordeiro, José Manuel Lopes (2009). “Ao serviço do povo venceremos”. A oposição estudantil nos últimos anos do fascismo (1969-1974)», Boletim Cultural de Vila Nova de Famalicão, III Série, no 5, pp. 119-158.

Coelho, João Paulo Borges (2013). «Politics and Contemporary History in Mozambique: A Set of Epistemological Notes», Kronos, 39, pp. 20-31.

Comaroff, Jean; Comaroff, John (2012). «History On Trial: Memory, evidence, and the forensic production of the Past». En: Jean Comaroff; John Comaroff (orgs.), Theory from the South: Or, How Euro-America is Evolving Toward Africa, Boulder-London: Paradigm Publishers.

Dussel, Enrique (1995). The Invention of the Americas: Eclipse of "the Other» and the Myth of Modernity, New York: Continuum.

Fanon, Frantz (1952). Peau noire, masques blancs, Paris: Seuil.

Felê, Buanga (1956). "O que é o lusotropicalismo?», Para Todos, 23 de Mayo de 1956, Casa Comum (http://casacomum.org/cc/visualizador?pasta=04352.010.002\#!2)

Furtado, Cláudio Alves (2016). «Cabo Verde e as quatro décadas de independência: dissonâncias, múltiplos discursos, reverberações e lutas por imposiçóes de sentido à sua história recente», Estudos Ibero-Americanos, 42, 3, pp. 855-887.

Garcia, José Luís y Castro, José (1995). "A Batalha e a Questão Colonial», Ler História, 27-28, pp.125-146.

Gomes, Carlos Matos (2004). «Quotidianos da Guerra Colonial». En: Themudo Barata, Manuel y Teixeira, Nuno Severiano (eds.). Nova História Militar de Portugal, Lisboa: Círculo de Leitores.

Loff, Manuel (2014). «Estado, democracia e memória: políticas públicas e batalhas pela memória da ditadura portuguesa (1974-2014)». En: Loff, Manuel; Soutelo, Luciana y Piedade, Filipe, Ditaduras e Revolução. Democracia e Políticas da Memória, Coimbra: Almedina.

Lourenço, Eduardo (2014). O colonialismo como nosso impensado. Organización y prefacio de Margarida Calafate Ribeiro e Roberto Vecchi, Lisboa: Gradiva. 
Madeira, João (2013). História do PCP. Das Origens ao 25 de Abril, Lisboa: Tinta-da-China.

Manya, Judith (2004). Le Parti Communiste Portugais et la Question Coloniale 19211974. Thèse pour le doctorat en Science Politique, Bourdeaux: CEAN.

Martins, Bruno Sena (2013). «Guerra e Memória Social: a deficiência como testemunho», Fractal: Revista de Psicologia, 25, 1, pp. 3-22.

Martins, Bruno Sena (2016). «Corpos-memórias da Guerra colonial: os Deficientes das Forças Armadas e o restolhar de asas no telhado». En: António Sousa Ribeiro e Margarida Calafate Ribeiro (orgs.). Geometrias da Memórias: Configuraçóes Pós-coloniais, Porto: Ediçóes Afrontamento, pp. 305-325.

Martins, Bruno Sena (2018). «Liberdade / Diáspora. A cronologia universal da descolonização da história», Memoirs Newsletter, 25, pp. 1-4.

Martins, Susana (2005). Socialistas na Oposição ao Estado Novo, Cruz Quebrada: Casa das Letras.

Meneses, Maria Paula; Rosa, Celso Braga; Martins, Bruno Sena (2017). «Colonial Wars, Colonial Alliances: The Alcora Exercise in the Context of Southern Africa», Journal of Southern African Studies, 43, 2, pp. 397-410.

Messiant, Christine (1998). "“Chez nous, même le passé est imprévisible”: l'expérience d'une recherche sur le nationalisme angolais», Lusotopie, 5, pp. 157-197.

Mudimbe, V. Y. (1988). The invention of Africa: gnosis, philosophy, and the order of knowledge, Bloomington: Indiana University Press.

Nkrumah, Kwame (1973). «Declaration to the Colonial Peoples of the World», Revolutionary Path, Nueva York: International Publishers.

Neves, José (2008). Comunismo e Nacionalismo em Portugal. Política, Cultura e História no século XX, Lisboa: Tinta-da-China.

Peralta, Elsa (2013). «A composiçáo de um complexo de memória: o caso de Belém, Lisboa». En: Nuno Domingos y Elsa Peralta (org.). Cidade e Império. Dinâmicas Coloniais e Reconfiguraçôes Pós-Coloniais, Lisboa: Ediçóes 70, pp. 361-414.

Pires, Rui Pena et al. (1987). Os Retornados: um Estudo Sociográfico, Lisboa: IED - Instituto de Estudos para o Desenvolvimento.

Quijano, Aníbal (2005). Colonialidade do poder, Eurocentrismo e América Latina, Buenos Aires: CLACSO.

RajAGOPAL, Balakrishnan (2009). "The International Human Rights Movement Today», Maryland Journal of International Law, 24 (1): pp. 56-62.

Rodrigues, Fátima da Cruz (2013). «A desmobilização dos combatentes africanos das Forças Armadas Portuguesas da Guerra Colonial (1961-1974)», Ler História, n. ${ }^{\circ}$ 65.

Rosas, Fernando (2012). Salazar e o Poder. A arte de saber durar, Lisboa: Tinta-da-China. 
Rosas, Fernando (2016). «História, (des)memória e hegemonia», História e Memória. "Última Lição" de Fernando Rosas, Lisboa: Tinta-da-China, pp. 41-81.

SANTos, Boaventura de Sousa (2014). "Más allá del pensamiento abismal: de las líneas globales a una ecología de saberes». En: Santos, Boaventura de Sousa e Meneses, Maria Paula (org.). Epistemologias del Sur (Perspectivas), Madrid: Akal, pp. 21-66.

Santos, Boaventura de Sousa (2018). The end of a cognitive empire: the coming of age of epistemologies of the south, Durham: Duke University Press.

SANTos, Boaventura de Sousa (2016). «Para uma nova visão da Europa: aprender com o Sul», Sociologias, no 43, set/dez, pp. 24-56.

SAID, Edward W. (1993). Culture and imperialism, Nueva York: Knopf.

STOLER, Ann Laura (2008). «Imperial Debris: Reflections on ruins and ruination», Cultural Anthropology, no 23 (2), pp. 191-219.

Troiullot, Michel-Rolph (1995). Silencing the Past. Power and the Production of History, Boston: Beacon Press.

Varela, Pedro y Pereira, José (2019). "As origens do movimento negro e da luta antirracista em Portugal no século XX: a geração de 1911-1933», Buala. En: http:// www.buala.org/pt/mukanda/as-origens-do-movimento-negro-e-da-luta-antirracista-em-portugal-no-seculo-xx-a-geracao-de-1

Winter, Jay (20I0). "Thinking about silence», in Ben-Ze'ev, Efrat; Ginio, Ruth; Winter, Jay, Shadows of War. A Social History of Silence in the Twentieth Century, Cambridge: Cambridge University Press, pp. 3-31.

ReCiBido: 8/05/20I9

ACEPTADO: 2I/II/20I9

\section{(C) $\odot \Theta \Theta$}

ENDOXA está bajo una licencia de Creative Commons Reconocimiento-NoComercial-SinObraDerivada 4.0 Internacional 
